\title{
De las bellas artes a la composición arquitectónica
}

\section{From fine arts to architectural composition}

DOI: $10.46932 / \mathrm{sfjdv} 2 \mathrm{n} 4-025$

Received in: March 1st, 2021

Accepted in: May 30th, 2021

\section{Lyda maritza Gamboa Leguizamón}

Magister en Diseño Sostenible - Especialista en Restauración y Conservación del Patrimonio -

Especialista en accesibilidad

Domicilio completo: Tunja, Boyacá - Colombia

Correo electrónico. arq.lyda@gmail.com

\section{RESUMEN}

El proceso compositivo en la proyectación arquitectónica puede ser considerado como uno de los mas complejos de abordar y uno de los mas complejos en argumentar, existen diversas teorías de diseño en arquitectura, principios ordenadores, de composición y de diseño, sin embargo, el resultado muchas veces no es el esperado, no es la representación del sentir y la esencia de quien y a quien lo proyecta.

El bloqueo comúnmente llamado "papel en blanco" al abordar una composición está dado por diversas condiciones, una de ellas es considerada como bloqueo emocional ${ }^{1}$, el no poder materializar la idea; dentro del proceso compositivo se establecen unos lineamientos basados en teorías, ellos ayudan a materializar la idea a partir de argumentos técnicos, sin embargo, la primera línea se produce antes de dibujarla ${ }^{2}$

El ser humano es muy perceptivo a los estímulos exteriores como la música, la danza, la pintura, el cine, Las Bellas Artes, ellas reviven experiencias, conocimientos, momentos, que permanecen en la mente representando una idea.

¿Entonces porque no hacer una sinergia de estos estímulos con la técnica arquitectónica?

Esta es la búsqueda en la investigación: establecer si las bellas artes como parte del proceso compositivo son una alternativa proyectual.

\footnotetext{
ABSTRACT

The compositional process in architectural planning can be considered as one of the most complex to address and one of the most complex to argue, there are various design theories in architecture, computer principles, composition and design, however, the result is many Sometimes it is not what is expected, it is not the representation of the feeling and the essence of who and to whom it is projected.

The blockage commonly called "blank paper" when approaching a composition is given by various conditions, one of them is considered an emotional blockage, not being able to materialize the idea; Within the compositional process, guidelines based on theories are established, they help to materialize the idea from technical arguments, however, the first line is produced before drawing it

The human being is very perceptive to external stimuli such as music, dance, painting, cinema, Fine Arts, they relive experiences, knowledge, moments that remain in the mind representing an idea.

¿So why not make a synergy of these stimuli with the architectural technique?

This is the search in research: to establish whether the fine arts as part of the compositional process are a project alternative.

${ }^{1}$ Carlos Churba, 'Desarrollo de la Creatividad' <http://blogsdelagente.com/carloschurba/> [accessed 22 April 2018

2 José María de Lapuerta, El croquis, proyecto y arquitectura: scintilla divinitatis, 7333, 1st edn (Madrid: Celeste Ediciones, 1997) <http://hdl.handle.net/123456789/6617>.
} 


\section{INTRODUCCIÓN}

«El arte es el recto ordenamiento de la razón»

Tomás de Aquino

Como miembro de la comunidad Dominicana considero que la cita de Santo Tomás, direcciona la “Linea Medular Institucional Fray Angélico”, relacionada con la sensibilidad artística y cultural, tema de la presente averiguación, dependiente de la Línea de Investigación de la Facultad de Arquitectura, Didáctica de la Arquitectura

La investigación pretende entender la relación de las ellas artes con la composición arquitectónica, para establecer un proceso de diseño mas versátil, ligado al impulso humano mediante estímulos dados por las bellas artes. Se establece una población de estudio en el ciclo básico del pregrado para hacerle seguimiento durante un semestre y evaluar los resultados.

El objetivo general es desarrollar de procesos de diseño que se puedan llegar a la composición arquitectónica desde las bellas artes.

Objetivos específicos:

- Generar opciones para abordar una composición.

- Hacer un vínculo asociativo entre las sensaciones y el impulso transmitido por cerebro a la mano.

- Enlazar las bellas artes como parte conceptual en la argumentación de una composición arquitectónica.

- Verificar experimentalmente el resultado de la composición con una de las bellas artes.

Como primera medida se establece la recolección de fuentes primarias sobre teorías que trate este tipo de estímulos en el ser humano; de tal manera que se respondan hipótesis para implementarlas en la práctica experimental de la composición.

El siguiente paso fue definir una metodología que permitiera ir evaluando resultados en tiempo real. Eso por cuanto la asignatura piloto tiene un espacio de tiempo académico a la semana y era necesario programar actividades como complemento al contenido de la misma.

En tercer lugar, evidenciar el proceso que se llevó a cavo durante el semestre para finalmente emitir los resultados que permitan hacer la verificación en el semestre siguiente.

\section{ANTECEDENTES}

Para empezar se toman algunos referentes teóricos para entender qué es el arte, el arte en la arquitectura, la creatividad, la imaginación la composición y las bellas artes: arquitectura, música, pintura, danza, literatura, escultura y cine. 
Aparentemente la definición de arte es abierta, subjetiva, discutible. Desde un marco histórico, Las bellas artes, es un término que se popularizó en el siglo XVIII, para referirse a las principales formas de arte que se desarrollaban principalmente por la interpretación de la estética, la idealización de la belleza y el buen uso de la técnica. "El arte es una actividad humana consciente capaz de reproducir cosas, construir formas, o expresar una experiencia, siempre y cuando, el producto de esta reproducción, construcción, o expresión pueda deleitar, emocionar o producir un choque"i.

Al remitirnos a la época de pensamiento medieval con la doctrina Santo Tomás muy clásica: “la idea operativa se estructura en base a determinados cánones y, si se opone a una mera imitación, esto puede ocurrir sólo mediante el recurso a un acto compositivo de recuerdos de experiencias anteriores, como el que se nos describe en los primeros versos de la epístola Ad Pisones de Horado"ii, se puede analizar cómo el arte visto desde la experiencia, está ligado a un pensamiento anterior, a un pensamiento producto de las vivencias y cierra su campo de acción a lo venidero del siglo XX.

Para Maritain, “los límites de la doctrina de Santo Tomás son bastante reducidos, y no podía olvidar la rica lección bergsoniana: por ello, aunque sea en una nota, en Art et Scolastique habla del proyecto de la obra, no sólo como conjunto de reglas objetivas y tradicionales, sino como «razón seminal», intuición y, por último, schéma dynamique (que afecta no solamente a la inteligencia, sino también a la imaginación y la sensibilidad del artista)" ${ }^{\text {"iii }}$.

Esta teoría Maritainiana pone el arte escolástico como una teoría del conocimiento que busca ampliar su significado con la poesía, y en definitiva, mientras que el arte es una operación práctica regulada por leyes de la inteligencia, la poesía es la emoción intencional, el fenómeno interno originario que anima desde dentro las reglas de arte. El arte empieza, por consiguiente, después, con «la inteligencia y la voluntad de elección ${ }^{\mathrm{iv}}$

A principios del siglo XX nace la línea de la escuela Alemana de la Psicología de la Gestalt que traduce groso modo la sicología de la forma, consiste en que la mente configura los elementos a través de canales sensoriales a una interrelación entre percepción visual y representaciones que guardamos en nuestra memoria; "el todo es más que la suma de las partes", esta corriente cuenta mucho con la imaginación y la percepción mas allá de los sentidos, según la filosofía de Kant, que asigna a la imaginación como condición subjetiva cuya materia proviene de estímulos y cuya forma impone el hacer desde esa imaginación en espacio y tiempo, impulsos psicológicos ${ }^{\mathrm{v}}$.

Al mismo tiempo el sentido del arte en arquitectura se hace visible en el renacimiento se vuelve humanista y da una respuesta a un contexto social ${ }^{\text {vi }}$; en el siglo XVIII se ve el valor artístico de la arquitectura considerándola una inspiración creativa y en 1971 con la real academia de arquitectura que impulsa a un conocimiento más exacto y una teoría más correcta, la composición es considerada como 
sinónimo de creación y orden en donde la sensibilidad y la razón van de la mano; la arquitectura del movimiento moderno busca unificar el arte y la técnica, se radica el concepto del arte como parte de vida misma y se lleva a concebir el hecho arquitectónico como una expresión de creatividad; sin embargo la complejidad funcional crea la necesidad de establecer procesos de diseño con un enfoque científico, medioambiental, de territorio y social ${ }^{\text {vii }}$.

El término creatividad no era considerado en la antigüedad clásica, sino hasta en siglo XVIII que fue asociado con el concepto de imaginación y en 1990 con las teorías de Tatarkiewicz. en donde se reconoce por la novedad de sus producciones "El hombre es creativo cuando no se limita a afirmar, repetir, imitar, cuando da algo de sí mismo" viii

El término composición significa básicamente "organizar". La composición en referencia al lenguaje visual supone la organización de los elementos que forman el conjunto de imagen, con el fin de obtener un efecto de unidad y orden; según el diccionario de artes plásticas la composición responde a una organización estructural de sus elementos que responde a leyes perceptuales con integración y armonía.

La imaginación podemos tomarla también como la formación de imágenes mentales libres sobre el pasado o el futuro; son de tipo asociativo, que en muchos casos recrea experiencias vividas o experiencias deseadas con la característica de modificar la realidad a gusto propio. Su característica principal es un pensamiento creador no implantado, este no es percibido con anterioridad sensorialmente y transforma la realidad.

En la antigua Grecia, podían ser identificadas dos grandes líneas para clasificar las artes en dos grupos: uno apotelécticas, tales como la Pintura, escultura y Arquitectura, las cuales son producto únicamente de su autor para que la obra quede perfecta, y las Músicas o Prácticas, tales como la danza, la música y la poesía, que requieren de la interpretación y admiración de terceros para su validación ${ }^{\text {ix }}$. La literatura no era vista como un arte que se valiera de la palabra escrita sino mas bien como una necesidad de la mente para su oración, La Literatura con origen Latín es reconocida mucho después. Según Aristóteles las artes de clasifican es Mecánicas, las cuales utilizan las manos para su producción y las Liberales, que utilizan la razón ${ }^{\mathrm{x}}$. Con el modernismo, los siete oficios producto de la creación artística son denominados como Las bellas artes: Arquitectura, Música, pintura, Danza, Literatura, Escultura y cine, el teatro importante también considerado como la reunión de varias de ellas y aunque no esté incluido inicialmente.

Arquitectura: Como arte, tiene la virtuosidad de modificar el espacio respondiendo a proporción, integridad, adaptación, equilibrio y armonía buscando que el hábitat función, sea el apropiado según el caso y no haya mayor impacto al entorno. 
Música: "En un sentido estricto, podemos definir a la música como "sonido organizado". En esta organización pueden combinarse multitud de recursos, desde sonidos disonantes y consonantes, elementos aleatorios. Compases y formas estrictas hasta cintas magnetofónicas, medios digitales $e$ infinidad de fuentes productoras de sonido, como máquinas de vapor o el tráfico vehicular". xi

Pintura: "La pintura es el arte y la técnica de representar en una superficie plana cualquier objeto concreto visible o bien algo imaginario, sugerido por líneas y/o colores". xii

Escultura: "La palabra Escultura procede del latín sculpere, "esculpir". Es el arte de crear formas figurativas o abstractas, tanto en bulto como en relieve. Las obras escultóricas se expresan mediante formas sólidas, reales, volumétricas; pues ocupan un espacio tridimensional: tienen alto, ancho y profundidad". xiii

Danza: "La danza es una expresión artística debido a que en ella se observa creación y expresión, además de la transmisión del mundo subjetivo que se objetiva en un producto que no persigue directamente la satisfacción de una necesidad utilitaria. Constituye un lenguaje (determinado social e históricamente) en donde el mensaje se transmite por medio de símbolos elaborados con el movimiento del cuerpo human" $0 .{ }^{\text {iv }}$

Literatura: "La palabra literatura proviene del término latino litterae, que hace referencia al conjunto de saberes para escribir y leer bien. El concepto está relacionado con el arte de la gramática, la retórica y la poética. La literatura es el arte que emplea como medio de expresión una lengua. También se utiliza el término para definir al conjunto de las producciones literarias de una nación, de una época o de un género (como la literatura persa, por ejemplo) y al conjunto de obras que tratan sobre un arte o una ciencia (literatura deportiva, literatura jurídica, etc.) '” ${ }^{\mathrm{xv}}$

Cine: fue incluido en 1911 con el manifiesto de las siete artes por Riccioto Canudo, "La cinematografía comúnmente conocida por su abreviatura "cine" es un arte que se encarga de transmitir de manera veloz, imágenes o fotogramas para dar la sensación de movimientos. El término cinematografía deriva de dos palabras de origen griego, la primera es "kiné" cuyo significado es "movimiento" y la segunda es "grafos" que quiere decir imagen, por ello se puede decir que la cinematografía son imágenes en movimiento"xvi.

\section{METODOLOGÍA}

Para establecer un proceso investigativo en este caso explorativo, experimental ${ }^{\mathrm{xvii}} \mathrm{y}$ aplicado, se hizo necesario formular ejercicios de proceso compositivo a partir de las bellas artes, intuyendo su repuesta de estimulo a partir de los significados teóricos deductivos y lo que expresan en la cotidianidad, aplicarlo a grupos de estudiantes en clase de teoría de la composición, asignatura que hace parte de la malla curricular del pensum 2009 del programa de Arquitectura de La Universidad Santo Tomás Seccional Tunja, en segundo semestre vigente en el año 2015, periodo de la investigación.

Un primer momento de la investigación tiene como fin investigar sobre las teorías de arquitectura aplicadas en estos espacios académicos, un segundo memento abordar las bellas artes como herramienta sensorial, un tercer momento establecer un proceso para aplicarlo en clase, compararlo con el tradicional y como ultimo momento sacar conclusiones de los resultados obtenidos par poder saber si es acertado 
utilizar otro método en la producción de la composición.

\section{EL PROCESO}

El inicio:

Dentro de la asignatura piloto mencionada anteriormente, Teoría de la Composición, se desarrollaron ejercicios prácticos compositivos para ver la aplicación de los conceptos dados en clase, como las teorías de composición de Ching, Wucius Wong, Kandinsky, de las que se determinan patrones importantes en la argumentación y razón de ser en el diseño, estas teorías tienen como fin mostrar herramientas para comprender la espacialidad, proporción y técnica, se explican principios ordenadores tales como Punto, Línea, eje, plano; principios de composición como simetría, jerarquía, ritmo, repetición y principios de diseño como unidad, equilibrio, contaste, armonía, teoría del color, todos ellos muy importantes.

La necesidad:

Como ejercicio práctico cada estudiante desarrolló una composición partiendo de estos principios para explicarla en la siguiente sesión; es acá donde el vacío y el papel en blanco se hizo presente, los estudiantes expresaron su frustración al no saber por donde comenzar, al no saber que hacer, que desarrollar a que responder, entendían los términos muy bien pero llevarlos a un papel la sesión que aconteció a esta no fue positiva, no lograron llegar con un resultado compositivo optimo los pocos que desarrollaron la composición, su explicación fue breve y fue manifestada en un formalismo de principios muy sobrio en representación a terminología vista en clase: si pretendían un equilibrio lo representaron a partir de una simetría con movimientos tímidos tratando de no salir del patrón común, sin experimentar, sin duda hubo unas composiciones muy armónicas, proporcionadas, interesantes pero sin transmitir nada.

\section{Proceso Experimental:}

A partir de este resultado, es que se implementa la introducción de las bellas artes dentro del diseño compositivo como método de proceso, buscando ese sentir y ese estímulo que puede proyectarse en una obra producto de la creatividad. Si bien cualquiera de las bellas artes es rica en su esencia, en este trabajo inicial se formula con el arte de la música.

La música tiene la particularidad dentro de las bellas artes de ser muy estimulante y producir sensaciones de forma rápida, inmediata, se pensaría que de forma inconsciente aunque no es así, la música une, la música identifica, con la música se expresan los mas sinceros sentimientos, hay un lenguaje universal a través de ella, con la música muchas personas pueden expresar y sentir, por esto fue la elegida 
como prueba piloto; La música y la arquitectura son muy afines en su estructura compositiva, comparten principios como: simetría, ritmo, tiempo, espacio, movimiento, armonía, articulación, proporción.

Como arte Música o Practica según la cultura Griega, la música requiere de un interprete para validar su obra, se pueden tener muchos resultados a partir de una sola pieza musical según el individuo, su entorno y los factores que afecten su bienestar; situación que se hace mas atractiva en el proceso propuesto puesto que solo será el estudiante enfrentado a su propio sentir. Como lo desarrolló el Arquitecto Gastón Clerec, en su Tesis de doctorado: "La Arquitectura es Música Congelada" en donde estudia esa conexión entre esas dos artes y demuestra ese sentir y esa emoción plasmada en las obras arquitectónicas mostrando ese instante en que la música intervino y fue parte fundamental en el proceso.

Planteamiento Metodológico:

Se considera necesario hacer una sensibilización gradual, se plantea el ejercicio para cuatro sesiones: la primera sesión se explica la metodología para realizar un ejercicio compositivo desde una sensación y se les hace pensar en su melodía favorita; se socializan varias opciones buscando respuesta al porqué de su elección, haciéndolos consientes de la sensación en ellos, del estimulo; en seguida se van con la tarea de escuchar esa melodía el mayor tiempo posible, en diferentes horas, en diferentes momentos, con diferentes personas; al tiempo de escucharlas es necesario que lleven una bitácora de notas o gráficos, en la que debían analizar que producía esta melodía en ellos: estados de ánimo, estados de compañía, gustos de comida y bebida, gustos en horas del día, sensaciones, emociones.

En la siguiente sesión organizan un mapa mental o memoria descriptiva que explique esas notas con este material producto de si mismos, las imágenes llegan a su mente y luego al escucharla solo tenían que dejarse llevar por todo su producto sensorial y trasladarlos del cerebro a la mano, en una representación en dos dimensiones; luego a tres dimensiones, así hacen evidente el sentimiento y estimulo mas fuerte y empiezan a llevar ese significado a líneas como un boceto o idea inicial.

En la tercera sesión desarrollaron y evolucionaron la idea con el soporte técnico y teórico en dos dimensiones y en tres dimensiones, escogiendo colores, materiales, formas por su significado; finalizando en una última sesión para mostrar el resultado y hacer una exposición del trabajo. Imágenes 1 y 2 
Ilustración 1: Proceso de diseño - socialización
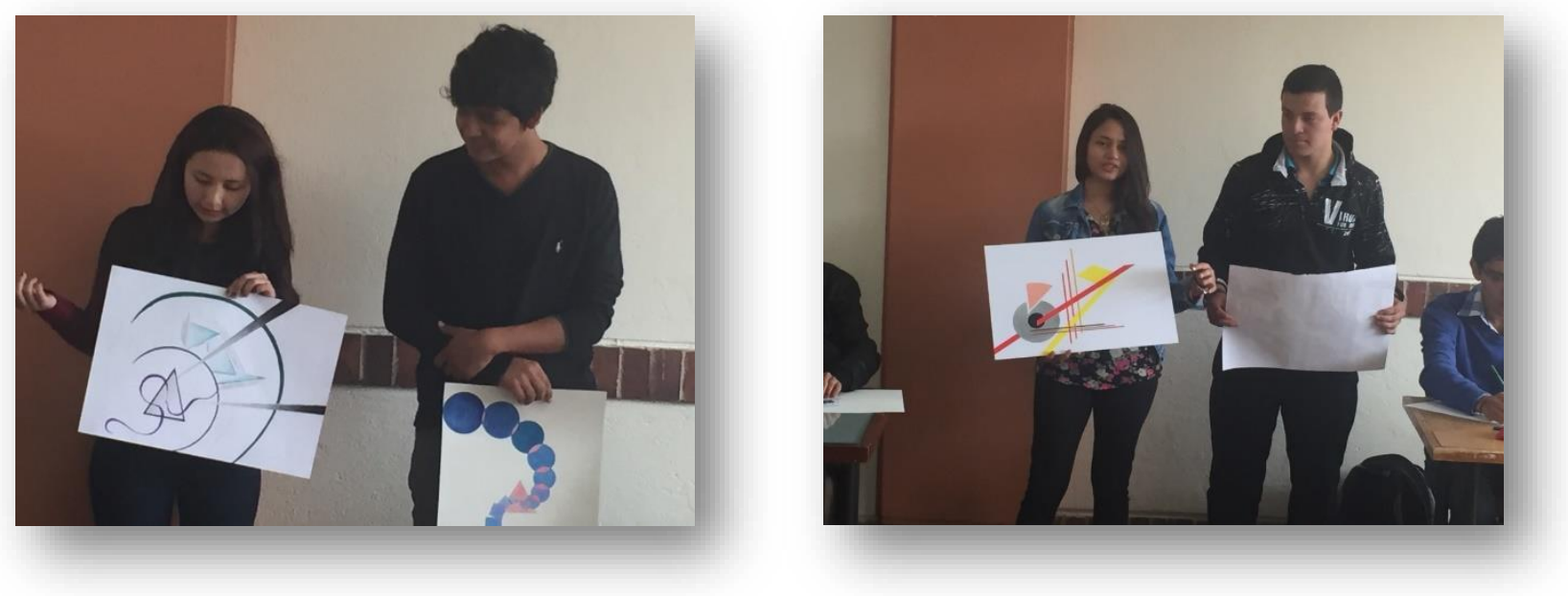

El resultado:

Desde las fases iniciales del ejercicio planteado los estudiantes se muestran motivados al sentir esa identificación con el trabajo a realizar y su individualidad. Eso les permite explorar mas en el diseño y conocerse un poco mas y conectarse mas consigo mismo, es de aclarar que ese reconocimiento se da progresivamente y no es tan extrovertido y sencillo para algunos. Hay quienes guardan celosamente sus pensamientos y sentimiento y solo hasta la muestra del resultado final dejan ver su trabajo.

Desde las percepciones de los estudiantes y la aceptación del trabajo es positivo, aparte de conocerse mas como personas entienden y dan sentido a los que hacen. Se dispuso de dos sesiones para la exposición de sus trabajos pues tiene mucho que contar y argumentar, aplican con mas sentido los principios teóricos y no se proponen a utilizarlos sino que brotan de su subconsciente de forma asociativa.

Comenzaron por reproducir la melodía escogida y mientras esta era escuchada se contemplaba el trabajo elaborado, el volumen es graduado por los mismos estudiantes quienes cuando lo creyeron pertinente lo disminuyeron para hablar sobre el desarrollo y explicar cada elemento.

Los mismos estudiantes fueron conscientes, que quien exponía, no solo hacía referencia a una melodía y su propia interpretación, sino que dejaban allí plasmado parte de su personalidad. En sus palabras: su identidad plasmada en el diseño.

En este momento se hace la preparación para implementar otra u otras de las bellas artes al proceso del diseño y ponerlo a estudio experimental con los grupos e trabajo, para valorar su comportamiento en la composición. 
Ilustración 2: Resultado del ejercicio compositivo - Música

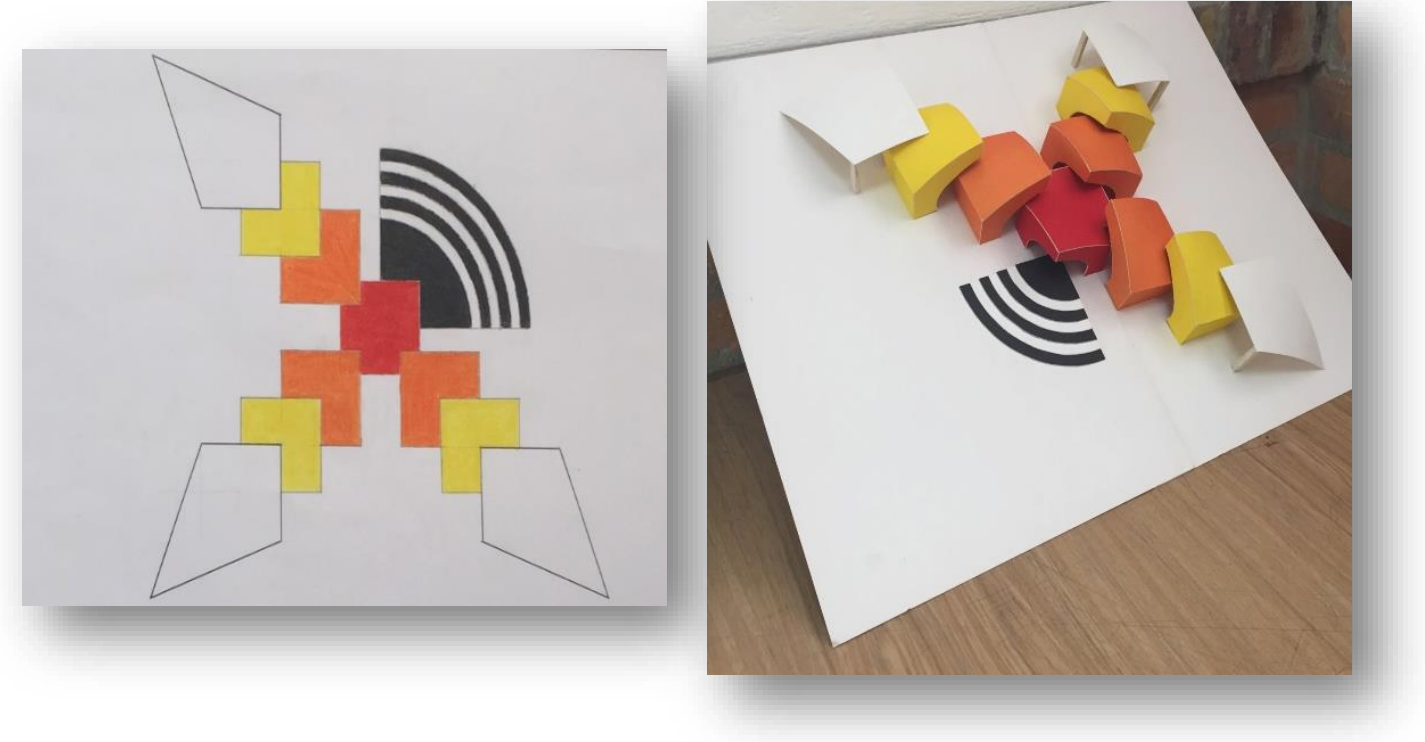

\section{CONCLUSIONES}

- Los resultados iniciales sobre el primer acercamiento para desarrollar un método de diseño son positivos; las sesiones de trabajo experimental fueron enriquecedoras y aportaron en el desarrollo e implementación en la asignatura.

- Fue evidente que los estudiantes ingresaron con una postura muy ingenua e intuitiva sobre el carácter de una composición y una vez realizado el taller su percepción cambió, su forma de abordar una composición se enriquece y ven como herramienta aplicativa este estimulo sensorial del arte.

- Fue muy productivo y benéfico que a partir del ejercicio propuesto, poder ayudar a los estudiantes a entenderse como personas, de esta manera pueden entender a otros y plasmar con mas claridad las ideas.

- La hipótesis de investigación es afirmativa, ya que se evidencia en los trabajos prácticos realizados y sus resultados que las bellas artes pueden formar parte del proceso de diseño como estimulo y vida de los proyectos arquitectónicos.

- Teniendo en cuanta la aceptación del proceso implementado, se incluyó dentro de la asignatura como modificación y mejora al contenido programático de la misma.

- Se pretende incluir otra u otras artes al proceso para poder dar mas herramientas al proceso compositivo y evaluar los resultados, con futuras nvestigaciones. 


\section{BIBLIOGRAFÍA}

Arnheim, Rudolf, La Forma Visual de La Arquitectura, 2da edición (Gustavo Gili, 2001)

Carlos Churba, 'Desarrollo de la Creatividad' <http://blogsdelagente.com/carloschurba/> [accessed 22 April 2018]

ENCARNACIÓN, Sra Dña M, and CASAS RAMOS, 'La Arquitectura es Música Congelada', tesis doctoral, 2003, 964

F.M., 'La creatividad como clave del futuro', Facundo Manes, 2013 <https://facundomanes.com/2013/08/05/la-creatividad-como-clave-del-futuro/> [accessed 23 April 2018] Hernández Sampieri, Roberto, Carlos Fernández Collado, and Pilar Baptista Lucio, Metodología de la investigación (México: McGraw-Hill, 2007)

Jiménez Correa, Susana, El Proyecto Arquitectónico, Aprender Investigando, 2006

Lapuerta, José María de, El croquis, proyecto y arquitectura: scintilla divinitatis, 7333, 1st edn (Madrid: Celeste Ediciones, 1997) <http://hdl.handle.net/123456789/6617>

‘QQué es Cine? - Su Definición, Concepto y Significado' <http://conceptodefinicion.de/cine/> [accessed 4 June 2018]

Santini, Carlotta, 'Un certamen entre culturas. Friedrich Nietzsche sobre oralidad y literalidad', 2017, 27

Tatarkiewicz, W., Historia de seis ideas. Arte, belleza, forma, creatividad, mímesis, experiencia estética (Madrid: Tecnos, 1990)

Umberto Eco, La Definición del Arte (España: Ediciones Martínez Roca, S.A., 1970) 
${ }^{\mathrm{i}}$ Tatarkiewicz, W., Historia de seis ideas. Arte, belleza, forma, creatividad, mímesis, experiencia estética (Madrid: Tecnos, 1990). Pg 67

ii Umberto Eco, La Definición del Arte (España: Ediciones Martínez Roca, S.A., 1970). Pg. 107

iii Umberto Eco.

iv Cfr. A. et S., notas 130 y 138; y Frontières, p. 33.

v Arnheim, Rudolf, La Forma Visual de La Arquitectura, 2da edición (Gustavo Gili, 2001).

vi Jiménez Correa, Susana, El Proyecto Arquitectónico, Aprender Investigando, 2006.

vii F.M., 'La creatividad como clave del futuro', Facundo Manes, $2013<$ https://facundomanes.com/2013/08/05/la-creatividadcomo-clave-del-futuro/> [accessed 23 April 2018].

viii Tatarkiewicz, W.

ix Sra Dña M ENCARNACIÓN and CASAS RAMOS, 'La Arquitectura es Música Congelada', tesis doctoral, $2003,964$.

${ }^{x}$ Carlotta Santini, 'Un certamen entre culturas. Friedrich Nietzsche sobre oralidad y literalidad', $2017,27$.

${ }^{x i}$ Latham, Alison. Diccionario enciclopédico de la música. Fondo de Cultura Económica. México 2008. Pág. 29

xii Cantú Delgado, Julieta de Jesús, y Heriberto García Martínez, Historia del Arte, Editorial Trillas, México, 2005, Pág.12

xiii Diccionario de la Real Academia de la Lengua Española (RAE)

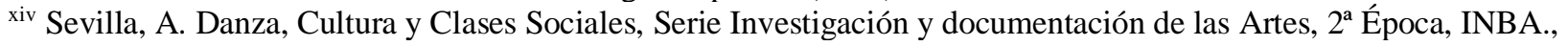
1990.Pag. 59.

${ }^{x v}$ Diccionario de la Real Academia de la Lengua Española (RAE)

xvi ‘¿Qué es Cine? - Su Definición, Concepto y Significado’ <http://conceptodefinicion.de/cine/> [accessed 4 June 2018 ].

xvii Roberto Hernández Sampieri, Carlos Fernández Collado, and Pilar Baptista Lucio, Metodología de la investigación (México: McGraw-Hill, 2007). 